\title{
Effects of resistance exercise in prostate cancer patients
}

\section{A systematic review update as of March 2020}

\author{
Andrej Zdravkovic $\cdot$ Timothy Hasenöhrl $\cdot$ Stefano Palma $\cdot$ Richard Crevenna (iD
}

Received: 8 April 2020 / Accepted: 27 June 2020 / Published online: 17 July 2020

(C) The Author(s) 2020

\begin{abstract}
Summary
Purpose The aim of this systematic review is to provide an update on the effects of resistance exercise (RE) in patients with prostate cancer (PCa), with special attention to the effects on sexual health.

Methods A systematic search of the literature was conducted in March 2020 using the databases PubMed, MEDLINE, EMBASE, SCOPUS and the Cochrane Library. Only randomized, controlled trials published after 31 December 2016 were included in this update. Additionally, articles from current and previous reviews were utilized to provide a brief summary of the effects on sexual health.

Results A total of 10 articles met the inclusion criteria, of which 5 were identified as independent studies. The remaining five articles presented additional data for studies, which have already been included. The identified studies further strengthened the evidence for positive effects on muscle strength, body composition and physical function. Positive effects on bone mineral density were apparent only when RE was combined with impact training. One article reported an improvement in fatigue and health-related quality of life. Only one study examined the effects of RE in isolation and three articles indicated positive effects of exercise on sexual health.

Conclusion Recent evidence supports the use of RE in PCa patient rehabilitation as a countermeasure for
\end{abstract}

\footnotetext{
All authors are employees of the Medical University of Vienna, Austria, and the preparation of this review took place within the scope of their regular scientific work.
}

treatment side effects. Further research is necessary to ascertain the optimal delivery methods and illuminate the effects on health-related quality of life (HRQOL), fatigue and sexual health.

Keywords Resistance training - Prostatic neoplasms . Androgen antagonists · Sexual health · Systematic review

\section{Introduction}

Prostate cancer $(\mathrm{PCa})$ is the most common malignancy in men [1] and shows the highest incidence rates of all cancer entities both in North America [2] and Austria [3]. It is responsible for the second most frequent cancer-related deaths in the USA [1, 2]; however, this is only because of the high absolute number of PCa patients, as the 5-year and 10year survival rates nowadays are well over $90 \%$ in developed countries [1, 4].

Although over $70 \%$ of men aged between 70 and 79 years will show histologic evidence of PCa, for the majority it is no longer the cause of death [1]. Therefore, for the majority of PCa patients their cancer has become a chronic, life-long, long-term disease. This increases the importance of supportive care in this patient population. A number of systematic reviews and meta-analyses have shown increases in quality of life [5], physical function and body composition [6] in PCa patients when conducting a resistance exercise (RE) program. From the perspective of exercise medicine $\mathrm{RE}$ is particularly beneficial for PCa patients as the side effects of their treatment often lead to a decrease in muscle mass and hence loss of physical function and increase of metabolic risk [7, 8] and RE is a potent intervention to counteract these complications [6]. 
Another major side effect of PCa treatment, particularly androgen deprivation therapy (ADT), is sexual dysfunction [9]. Sexual dysfunction finds its expression for the patients in decreased sexual desire, alone or together with erectile dysfunction, as well as absent orgasm [10]. The use of ADT is a major part of PCa treatment but alters men's sexuality via loss of libido, the aforementioned erectile dysfunction, and testicular atrophy [11]. Treatment strategies for sexual dysfunction in PCa patients focus mainly on the treatment of erectile dysfunction after primary therapy; however, the sexuality issues of PCa patients are far more complex than erectile dysfunction alone and therefore require a multimodal treatment approach [12]. With its complex effects on various domains, such as physical fitness, quality of life, and perception of masculinity, RE has been proposed as a potentially effective treatment to maintain or even improve sexual health in PCa patients [13, 14].

Therefore, the primary aim of the current systematic review was to provide a systematic review update and qualitative overview about RE intervention trials in PCa patients published since 31 December 2016. The secondary aim was to draw particular attention to the outcome measures of parameters of sexual health in all RE intervention trials in PCa patients published to date.

\section{Patients, materials and methods}

A systematic search of the scientific literature published from January 1966 until 31 March 2020 was conducted in the scientific databases PubMed, EMBASE, MEDLINE, SCOPUS and Cochrane Library using the search terms and Boolean operators ((resistance AND exercise) OR (resistance AND training) OR (strength AND training)) AND ((prostate AND cancer) OR (androgen AND (deprivation OR suppression) AND therapy)). Only randomized, controlled trials (RCT) examining the effects of RE in patients with PCa, published in English, were considered for this review. As this is an update to a previously published systematic review [5] and a meta-analysis [6], the main focus was on the recent studies published since 1 January 2017. The search strategy was congruent to those of the previous review papers of our research group [5, 6].

Search results were screened by title and abstract. Eligible articles underwent a full-text analysis. The literature search as well as the selection of suitable articles was performed independently by two experienced researchers. The individual evaluations of those researchers were brought together and, in cases of an unequal evaluation, discussed with inclusion of the senior author until a mutual evaluation was decided on. The number of patients per study arm, most relevant patient characteristics, details of the intervention and reported outcomes were extracted from each included independent study and the corresponding registered protocol. Furthermore, reported outcomes were extracted from the identified additional articles.

Risk of bias was assessed for the original studies published since 1 January 2017 utilizing the revised Cochrane risk of bias tool (RoB 2, current version as of 22 August 2019) at the level of the primary outcome for both the intention-to-treat effect and the per protocol effect.

In addition, included articles from the current and our previous reviews were searched and reports of effects on sexual health were extracted.

This review was conducted following the PRISMA reporting guidelines for systematic reviews and metaanalyses.

\section{Results}

\section{Literature search}

A total of 2088 articles were found and screened for eligibility by title and abstract. Of the articles 2000 did not meet the inclusion criteria, which left 88 articles for full-text analysis. Ultimately, 42 articles met the inclusion criteria of being relevant RE interventions with RE either as the sole exercise intervention or in combination with other exercise modalities in PCa patients [15-56]. Of those, 22 were identified as independent studies [15-31, 47-51], which published the primary outcomes in a specific population sample for the first time. In the other 20 articles, additional outcomes or analyses of former trials were published [32-46, 52-56]. Since 1 January 2017, 5 independent articles and 5 additional articles have been published. An overview of the selection process is shown in Fig. 1.

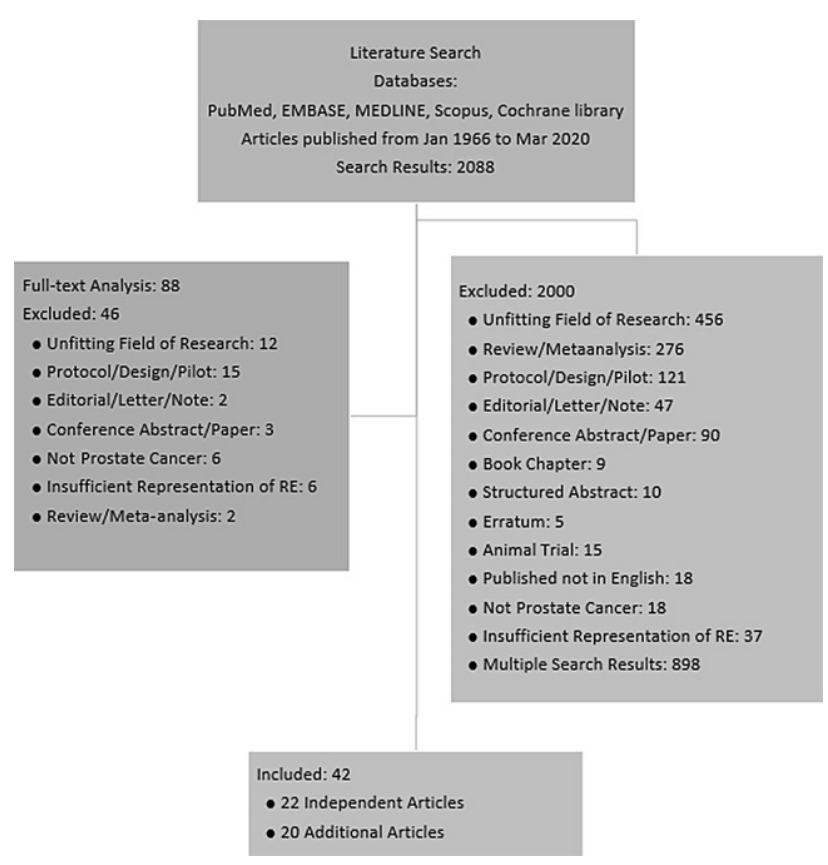

Fig. 1 Flowchart of the systematic literature search and selection. $R E$ resistance exercise 


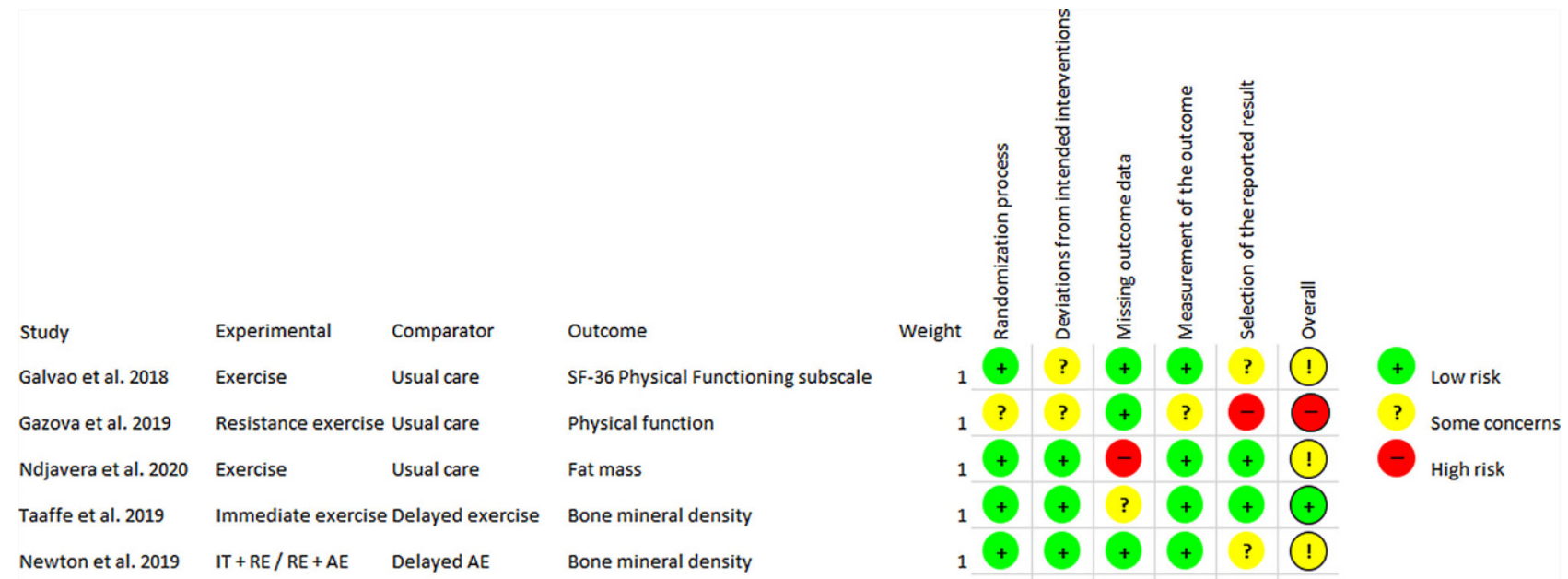

Fig. 2 Risk of bias analysis, intention-to-treat aspect. $R E$ resistance exercise, $A E$ aerobic exercise, $I T$ impact training

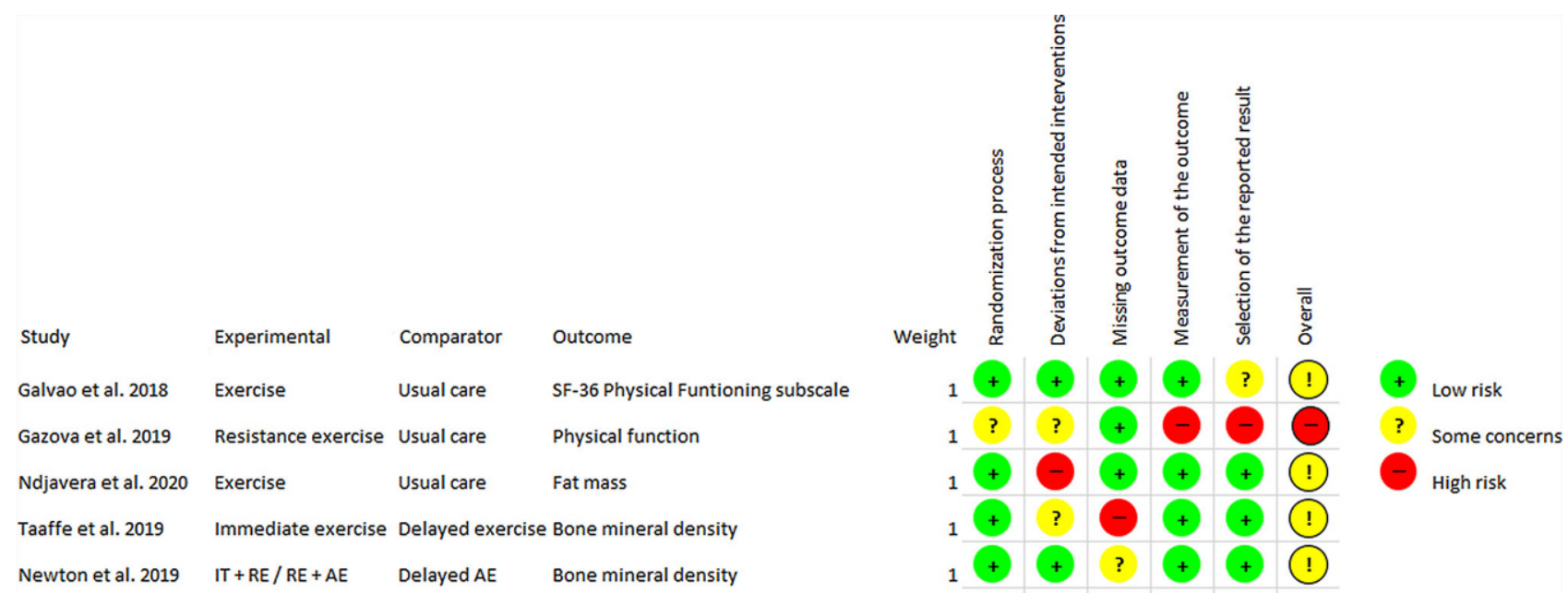

Fig. 3 Risk of bias analysis, per protocol aspect. $R E$ resistance exercise, $A E$ aerobic exercise, $I T$ impact training

\section{Risk of bias}

The risk of bias analysis showed that the five independent articles published after 1 January 2017 were predominantly of a moderate to high methodological quality, with the exception of one study being classified as having a high risk of bias [47]. The results of the analysis for both the intention-to-treat effect are shown in Fig. 2 and for the per protocol effect in Fig. 3.

\section{Level of evidence}

The level of evidence of the majority of the studies was graded as Ib, with the exception of one study, which was graded as IIb, due to low methodological quality. This study [47] suffered from a very small sample size, an insufficiently defined primary outcome, and within-group comparisons as the primary method of analysis. The level of evidence of the included studies is presented in Table 1.

\section{Independent articles}

Apart from strengthening the evidence for the positive effects of RE on muscle strength, body composition, cardiovascular capacity, physical functioning and fatigue [47-50,57], recent studies have indicated that a combination of RE and impact training (IT) decel-

Table 1 Level of evidence and type of exercise

\begin{tabular}{|l|l|l|l|}
\hline Study & Year & $\begin{array}{l}\text { Level of evi- } \\
\text { dence }\end{array}$ & $\begin{array}{l}\text { Type of exercise interven- } \\
\text { tion }\end{array}$ \\
\hline Gazova et al. [47] & 2019 & llb & RE only \\
\hline Galvao et al. [51] & 2018 & lb & RE+AE+FLEX \\
\hline $\begin{array}{l}\text { Taaffe et al. [50] } \\
2019\end{array}$ & lb & $\begin{array}{l}\text { RE+AE+IT vs. delayed } \\
\text { RE+AE+IT }\end{array}$ \\
\hline $\begin{array}{l}\text { Ndjavera et al. } \\
\text { [48] }\end{array}$ & 2020 & lb & RE+AE \\
\hline Newton et al. [49] & 2019 & lb & $\begin{array}{l}\text { RE+IT and RE+AE vs. } \\
\text { delayed AE }\end{array}$ \\
\hline
\end{tabular}

$R E$ resistance exercise, $A E$ aerobic exercise, IT impact training, FLEX flexibility training 


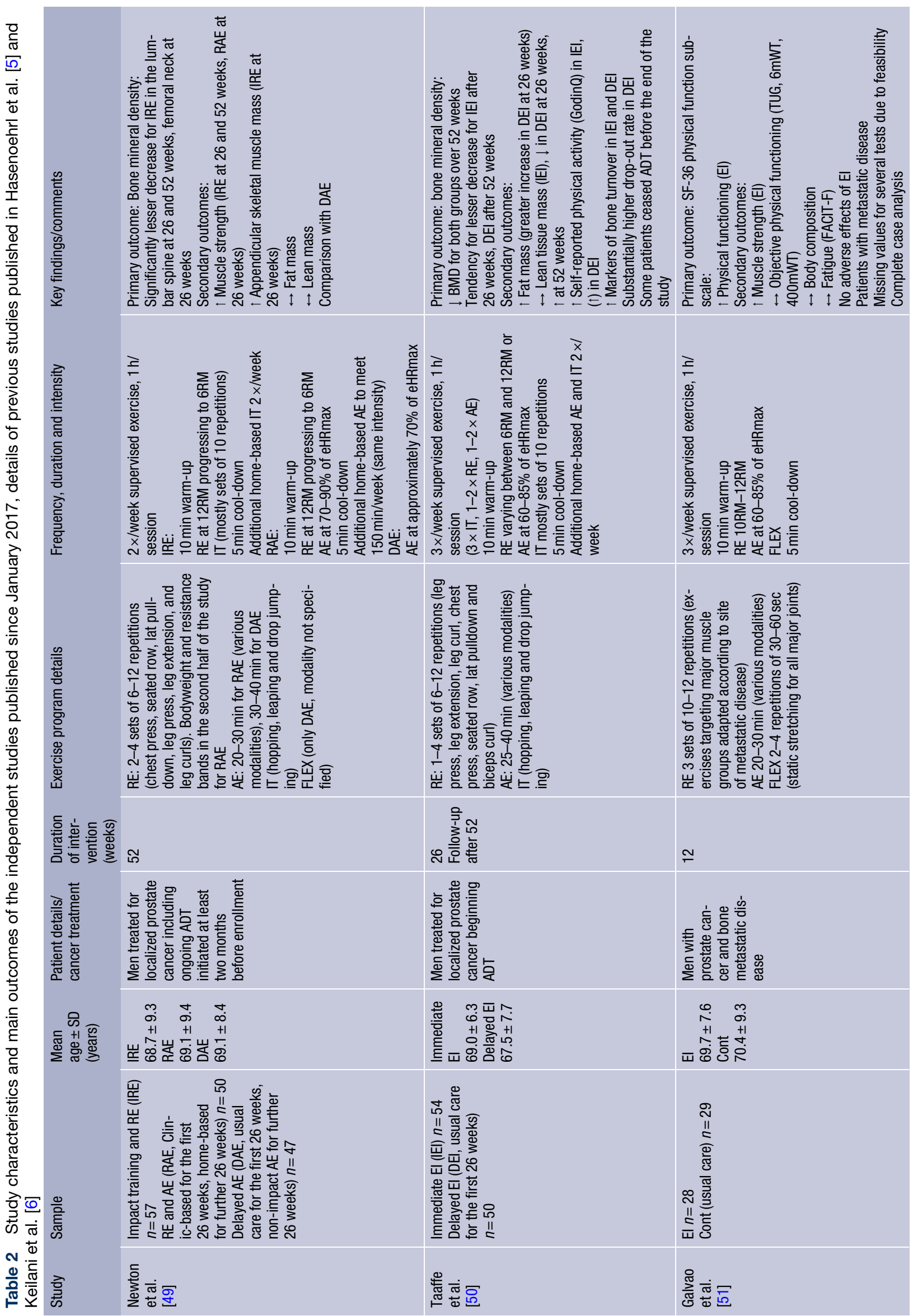




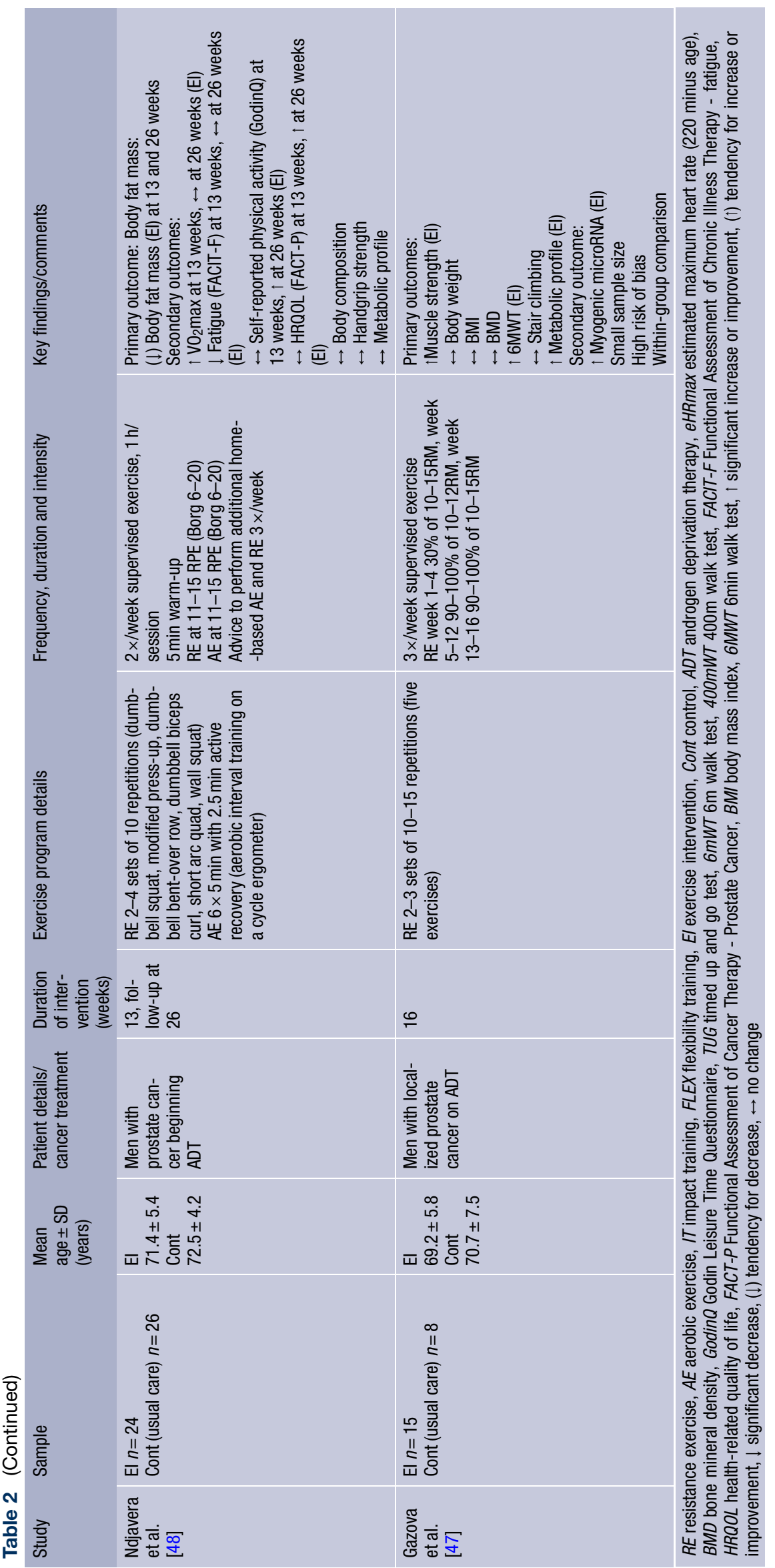


Table 3 Results of the additional articles published since January 2017, details of previous studies published in Hasenoehrl et al. [5] and Keilani et al. [6]

\begin{tabular}{|c|c|c|}
\hline Additional article & Expansion & Key findings/comments \\
\hline $\begin{array}{l}\text { Taaffe et al. [53] } \\
\text { Additional article of } \\
\text { Newton et al. [49] }\end{array}$ & Additional results & $\begin{array}{l}\text { I Fatigue (EORTC QLQ-C30 fatigue subscale, IRE at } 26 \text { and } 52 \text { weeks, RAE at } 52 \text { weeks, DAE at } 52 \text { weeks) } \\
\text { I Vitality (SF- } 36, \text { IRE, RAE and DAE at } 52 \text { weeks) } \\
\text { I Cardiorespiratory fitness ( } 400 \mathrm{mWT} \text {, IRE and RAE at } 52 \text { weeks, no change in DAE) } \\
\text { i Muscle strength (sum of chest press and leg press, IRE at } 26<52 \text { weeks, RAE at } 26 \text { and } 52 \text { weeks, DAE } \\
\text { at } 52 \text { weeks) } \\
\text { No group } \times \text { time interaction }\end{array}$ \\
\hline $\begin{array}{l}\text { Wall et al. [52] } \\
\text { Additional article of } \\
\text { Newton et al. [49] }\end{array}$ & $\begin{array}{l}\text { Additional results } \\
\text { RAE vs. DAE in the first } \\
26 \text { weeks }\end{array}$ & $\begin{array}{l}1 \text { Cardiorespiratory capacity }\left(\mathrm{VO}_{2} \mathrm{max}, \mathrm{RAE}\right) \\
\text { i Fat oxidation (RAE) } \\
\leftrightarrow \text { RMR } \\
\leftrightarrow \text { BP } \\
\leftrightarrow \text { Arterial stiffness } \\
\leftrightarrow \text { Metabolic profile } \\
\leftrightarrow \text { PSA and testosterone } \\
\text { i Lean tissue mass (RAE) } \\
\downarrow \text { Fat mass (RAE) } \\
\text { Between-group comparison }\end{array}$ \\
\hline $\begin{array}{l}\text { Fairman et al. [55] } \\
\text { Additional article of } \\
\text { Galvao et al. [51] }\end{array}$ & $\begin{array}{l}\text { Additional results } \\
\text { Training dose, adher- } \\
\text { ence and tolerance }\end{array}$ & $\begin{array}{l}\text { Actual training volume }=77.4 \% \text { of prescribed } \\
\text { Training interrupted ( } \geq 3 \text { consecutive sessions missed) in half of patients } \\
\text { Training missed ( } \leq 2 \text { consecutive sessions missed) in approximately } 90 \% \text { of patients. } \\
\text { Training dose modified in approximately } 85 \% \text { of patients }\end{array}$ \\
\hline $\begin{array}{l}\text { Edmunds et al. [56] } \\
\text { Additional article of } \\
\text { Galvao et al. [21] }\end{array}$ & $\begin{array}{l}\text { Cost-effectiveness } \\
\text { analysis }\end{array}$ & 26 weeks of supervised exercise for prostate cancer survivors probably not cost-effective \\
\hline $\begin{array}{l}\text { Newton et al. [54] } \\
\text { Additional article of } \\
\text { Taaffe et al. [50] }\end{array}$ & Additional results & $\begin{array}{l}\text { T Muscle strength } \\
\text { - In IEl at } 26 \text { weeks } \\
\text { - In DEI at } 52 \text { weeks } \\
\text { - No difference at } 52 \text { weeks } \\
\text { † Physical function } \\
\text { - } 6 \mathrm{mWT} \text { (only in IEI at } 26 \text { weeks) } \\
\text { - } 400 \mathrm{mWT} \text { (IEl at } 26 \text { weeks, DEl at } 52 \text { weeks) } \\
\text { - Stair climbing (IEl at } 26 \text { weeks, DEl at } 52 \text { weeks) } \\
\text { - Repeated chair rise (IEI at } 26 \text { weeks, DEl at } 52 \text { weeks) } \\
\text { - Significant difference only for } 6 \mathrm{mWT} \text { at } 52 \text { weeks } \\
\text { Between-group comparison }\end{array}$ \\
\hline $\begin{array}{l}\text { impact trainin } \\
\text { ake, RMR rest } \\
\text { rvention group } \\
\text { Q-C30 Europea }\end{array}$ & $\begin{array}{l}\text { ance exercise grou } \\
\text { ic rate, } B P \text { blood } p\end{array}$ & $\begin{array}{l}R A E \text { resistance and aerobic exercise group, DAE delayed aerobic exercise group, } \mathrm{VO}_{2} \max \text { maximal oxygen } \\
\text { ssure, PSA prostate-specific antigen, IEI immediate exercise intervention group, DEI delayed exercise } \\
400 \mathrm{~m} \text { walk test, } 1 \text { significant increase or improvement, } \downarrow \text { significant decrease, } \leftrightarrow \text { no change, EORTC } \\
\text { reatment of Cancer Quality of Life Questionnaire }\end{array}$ \\
\hline
\end{tabular}

erates the loss of bone mineral density (BMD) during ADT. Newton et al. [49] reported that a one yearlong exercise intervention (RE+IT) resulted in a significantly lesser decrease in BMD, specifically at the lumbar spine and the femoral neck; however, the latter only at 6 months. Taaffe et al. [50] reported similar findings, although the between-group difference did not reach statistical significance. Finally, Gazova et al. [47] reported no effect of 4 months of RE on BMD. The results of the included studies are presented in Table 2.

\section{Additional articles}

Of the five additional articles, three presented similar findings in relation to muscle strength, cardiovascular capacity, fatigue body composition and physical functioning [52-54]. Edmunds et al. [56] provided a costeffectiveness analysis of a 6-month intervention [21] and concluded that a clinic-based intervention should be expanded by a period of home-based exercise in order to achieve cost-effectiveness and that the inclu- sion of health-related quality of life (HRQOL) in the measurements might improve future economic evaluations. Fairman et al. [55] indicated that mere reporting of attendance might overestimate adherence to a RE protocol. The findings of the additional articles are presented in Table 3.

\section{Sexual health}

When looking at the outcomes regarding sexual health in all included studies, sexual health was reported as a secondary outcome in only three articles $[18,34,45]$. The instrument used in two of these $[18,34]$ was a disease-specific questionnaire (EORTC QLQ-PR25 - European Organization for Research and Treatment of Cancer Quality of Life Questionnaire-Prostate), whereas in the third [45], a modified questionnaire according to Druley et al. [58] was completed by PCa patients and their spouses. No objective measurements of sexual dysfunction were performed. Selfreported sexual function [18] as well as sexual activity and interest in sex [34] significantly improved in the 
Table 4 Results of studies assessing the effects of resistance exercise on sexual health in prostate cancer patients

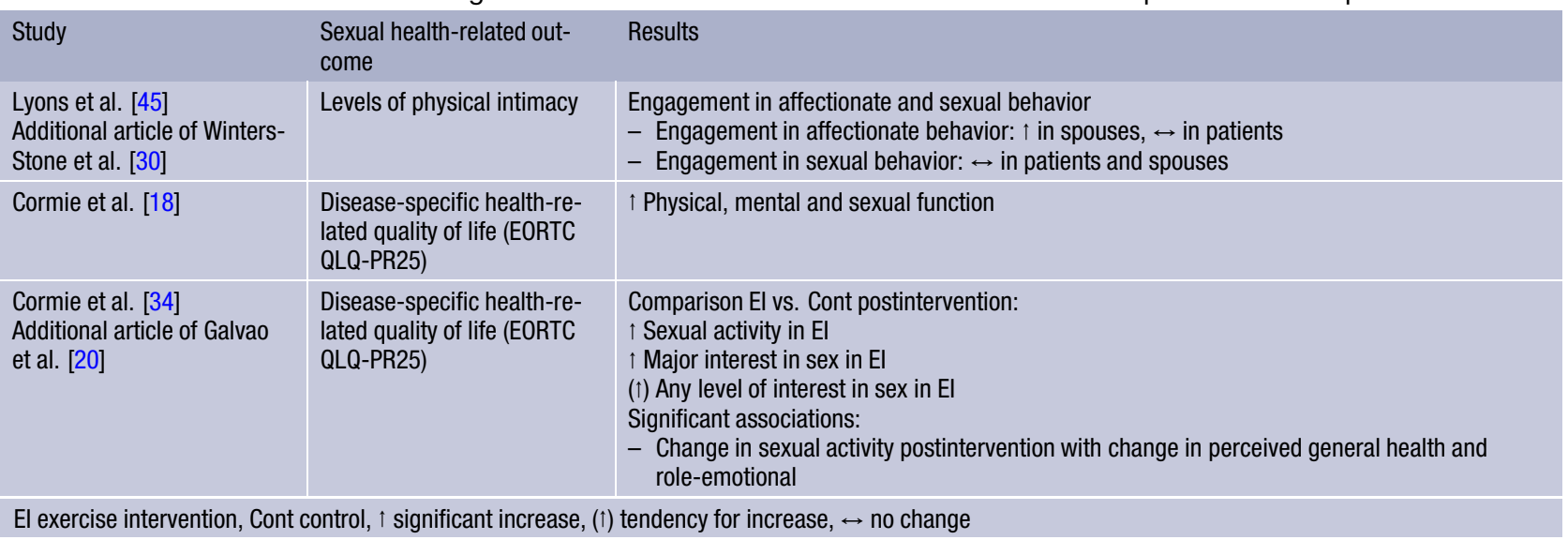

exercise intervention group. Partnered exercise led to an increased frequency of engagement in affectionate behavior in partners but not in PCa patients themselves. The results regarding sexual health are outlined in Table 4.

\section{Discussion}

Since January 2017, 10 articles have been published on the subject of RE in PCa patients: 5 independent studies and 3 additional articles expanded the evidence for the positive effects of RE on muscle strength, body composition, cardiovascular capacity, physical functioning and fatigue [47-50, 52-54, 57]. Of the independent studies two also indicated that a combination of RE and IT decelerated the loss of BMD during ADT.

Taaffe et al. [50] investigated the effects of an exercise intervention beginning approximately at the same time as ADT or 6 months later. The intervention, consisting of RE, aerobic exercise IT and stretching attenuated the loss of muscle mass and gain in fat mass. No effect on BMD was seen at 12 months, as it decreased in both groups; however, the partial cross-over design of the trial may have diminished the group differences. Even though the delayed intervention failed to attenuate the loss of BMD, it may be prudent to recommend an immediate initiation of exercise in this patient population, as bone metabolism is different and the recovery of BMD may be slower in older age [59].

The study by Galvao et al. [57] was the only one conducted in patients with metastatic disease. The exercise protocol, lasting 3 months and consisting of $\mathrm{RE}$, aerobic exercise and stretching, was adapted for each patient, according to site of bone lesions. Due to difficulties in performing the majority of the tests, only complete cases were analyzed. The exercise intervention resulted in significant increases in muscular strength and self-reported physical functioning. Most probably, the clinically most important finding was the overall good acceptance and tolerance of the RE intervention. For this particular patient popula- tion, interventions affecting the risk of fractures and falls are of great interest. In a recent international cohort study on community-dwelling older men, the risk of a major osteoporotic fracture was negatively correlated with walking speed, grip strength and appendicular lean mass [60]. Furthermore, a recent systematic review found that interventions implementing RE, coupled with balance and functional exercises, probably reduced the risk of falls in older adults [61]. Whether these findings can be extrapolated to a reduced risk of fractures and falls in PCa patients with bone metastases remains to be determined, but there is currently little evidence to suggest otherwise.

Ndjavera et al. [48] implemented a 3-month exercise intervention of RE and interval aerobic exercise at the start of ADT, with a follow-up at 6 months. Improvements in fat mass, cardiovascular capacity, selfreported physical activity and HRQOL were observed, which further support the notion of concurrent ADT and exercise, similarly to the findings of Taaffe et al. [50].

Newton et al. [49] reported the results of a threearmed, one year-long RCT on PCa patients during ADT. In the study RE was combined either with aerobic exercise or IT and compared with a delayed intervention group. Bone loss was significantly slower in the RE+ IT group at 6 months, but statistical significance was lost at 1 year for most sites. Interestingly, appendicular skeletal muscle mass improved only in the RE+ IT group, even though both RE regimens resulted in an increase in muscle strength. The possibility of interference of RE and aerobic exercise, as well as additional loading due to IT were discussed by the authors.

Gazova et al. [47] presented the findings of a small RCT examining the effects of 16 weeks of isolated RE in PCa patients on ADT. The authors noted an improvement in muscle strength, cardiovascular capacity and, as a secondary outcome, an increase in the plasma concentration of myogenic miRNA. The study exhibited several potential methodological limitations. The sample size was small, comprising 15 patients in the 
intervention group and 8 in the control group, which may have increased the probability of a type II error [62]. Moreover, no sample size calculation was reported, which limits the ability to estimate the statistical power of the depicted results. The RE intervention was not sufficiently defined according to the FITT formula (Frequency, Intensity, Time and Type of exercise), which in turn reduces the detailed estimation of the RE stimulus as well as the reproducibility of the trial [63]. A total of 19 primary outcome measures were reported, alongside 3 secondary outcome measures. According to the CONSORT statement [64], a large number of primary outcomes increases the probability of a type I error; however, whether a type I or type II error truly occurred, cannot be determined at this time point [62]. Nevertheless, contrary to what one would expect of an RCT, the primary method of analysis used were within-group comparisons instead of between-group comparisons. This defeats the purpose of an RCT and increases the probability of a type I error [65].

Regarding the results of the additional articles, reported secondary outcomes indicated improvements in muscle strength [53, 54], cardiovascular capacity [52-54], body composition [52], fatigue [52] and physical functioning [54]: however, the majority of the between-group comparisons showed no statistically significant differences. The reason for this might be that sample size calculations are always based on the primary outcome parameter which is normally published in the original article of a larger study. The secondary outcome parameters of additional articles can therefore never be treated with the same emphasis. These non-significant results are partly in line with the findings of our previous systematic review and meta-analysis [5, 6]. There, significant improvements in body composition, e.g. lean body mass and body fat, and in the $400 \mathrm{~m}$ walk time could be found in the pooled results although the individual results of the vast majority of the pooled studies did not show significant results [6]. Pooling and therefore metaanalysis regarding fatigue and HRQOL was, and still is, impossible due to the high variability of outcome measures of these outcomes [66]; however, as RE is known to reduce cancer-related fatigue in general [67] as well as physical functioning in older adults [68], it is most probably a matter of time and not of validity before specific recommendations, concerning the implementation of RE to counteract fatigue in PCa patients can be made.

Sexuality and sexual health are an important aspect of life for a large proportion of people, even in old age, although to a lesser degree [69, 70]. Sexual bother, which is defined as distress caused by sexual dysfunction, and erectile dysfunction are highly prevalent in PCa patients, especially when the treatment includes ADT [13]. Furthermore, erectile dysfunction has been linked to depression in this patient population [71]. It is important to note that sexual bother is not purely a result of erectile dysfunction, as it can persist even after the return of erectile function [72]. Other factors negatively influencing sexual health include body feminization, fatigue, depression and a reduced HRQOL [73]. Moreover, the fatfree mass index has in itself been associated with sexual desire in middle-aged men [74]. Beside pharmacological interventions, exercise [13] and psychological counselling, the latter including education on alternative sexual practices [75], have been suggested as complementary therapeutic approaches. Despite the high prevalence and subjective disease burden of sexual dysfunction and the ever increasing commonness of RE interventions during ADT, only three studies $[18,34,45]$ investigated the effects of RE on sexual function. Utilizing the EORTC QLQ-PR25, Cormie et al. [34] reported a significant increase in self-reported sexual activity and interest in sex following a 3month RE and aerobic exercise intervention. Interestingly, the change in sexual activity correlated to perceived general health and role-emotional. The same research group reported the results of a second trial 1 year later [18], indicating positive effects of a similar exercise intervention on the HRQOL and in particular the self-reported sexual function, as measured by the same questionnaire. Lyons et al. [45] however, employed a different approach and examined the effects of a partnered RE intervention on self-reported physical intimacy in PCa patients and their spouses. The participants answered questions regarding affectionate, as well as sexual behavior on a 4-level Likert scale, as modified from Druley et al. [58]. Curiously, only the females reported an increase in affectionate behavior, and neither reported an increase in sexual behavior. Nevertheless, the results of these studies indicated positive effects on sexual health in PCa patients, and one drew the conclusion that future research should put more emphasis on this field. As it is understandable that side-effects of PCa therapy, such as fatigue, loss of muscle mass and pelvic floor disorders influence sexual health, it is possible that many of these symptoms persist due to a vicious cycle of weakness, fatigue and depression, being that greater muscle strength has been associated with lower fatigue in cancer survivors [76]. In this respect, RE, primarily with its effects on muscle mass and strength, including that of the pelvic floor [77], may provide an efficient therapeutic approach for sexual dysfunction in PCa patients. The optimal timing, dose and modality should be the subject of future research.

However, recommendations regarding physical activity are not always met in the general population, in particular as pertaining to RE, and this omission has been associated with greater deficits in the activities of daily living [78]. Although certain idiosyncrasies of cancer patients, especially those with bone metastatic disease, have to be considered [79], public awareness of the positive effects of exercise, including the socioeconomic impact, should be raised [80] in order 
to facilitate the application of the findings of clinical studies.

The limitations of this systematic review update are primarily twofold. Firstly, half of the articles published since 1 January 2017 presented additional data of independent articles. As mentioned before, the outcome parameters of additional articles cannot usually be graded with the same statistical weight as the original papers whose sample size had been calculated for the primary outcome measure in the first place and not for the additional outcomes. Therefore, the results of those articles generally must be treated with caution. Secondly, due to the sparse literature and heterogeneous assessment methods no meta-analysis of parameters of sexual health was possible. Future research should work toward closing this knowledge gap and thus enabling a meta-analysis of the cumulative data and formulation of concrete recommendations.

\section{Conclusion}

The results of this systematic review update expand the evidence for the efficacy of RE in the rehabilitation of PCa patients. Recent data also indicated that a combination of RE and IT has positive effects on BMD during ADT. Only a few studies have investigated the effects of RE on sexual health in this patient population. Considering their promising results, RE as a strategy to approach sexual health-related side effects in PCa patients is inadequately represented in the current literature and deserves a larger focus in future research.

Acknowledgements This paper was written by an interdisciplinary team at the Department of Physical Medicine, Rehabilitation and Occupational Medicine, Medical University of Vienna, Austria.

Funding Open access funding provided by Medical University of Vienna.

\section{Compliance with ethical guidelines}

Conflict of interest A. Zdravkovic, T. Hasenöhrl, S. Palma, and R. Crevenna declare that they have no competing interests.

Ethical standards For this article no studies with human participants or animals were performed by any of the authors. All studies performed were in accordance with the ethical standards indicated in each case.

Open Access This article is licensed under a Creative Commons Attribution 4.0 International License, which permits use, sharing, adaptation, distribution and reproduction in any medium or format, as long as you give appropriate credit to the original author(s) and the source, provide a link to the Creative Commons licence, and indicate if changes were made. The images or other third party material in this article are included in the article's Creative Commons licence, unless indicated otherwise in a credit line to the material. If material is not included in the article's Creative Commons licence and your intended use is not permitted by statutory regulation or exceeds the permitted use, you will need to obtain permis- sion directly from the copyright holder. To view a copy of this licence, visit http://creativecommons.org/licenses/by/4.0/.

\section{References}

1. Gomella LG. Prostate cancer statistics: anything you want them to be. Can J Urol. 2017;24:8603-4.

2. Henley SJ, Ward EM, Scott S, Ma J, Anderson RN, Firth AU, et al. Annual report to the nation on the status of cancer, part I: national cancer statistics. Cancer. 2020;126(10):2225-2249.

3. Österreichisches Krebsregister (Stand 09.12.2019) und Todesursachenstatistik. Malignome (Neuerkrankungen pro Jahr) nach Lokalisation und Geschlecht, Österreich seit 2007. 2019. http://pic.statistik.at/web_ de/statistiken/menschen_und_gesellschaft/gesundheit/ krebserkrankungen/krebs_im_ueberblick/021806.html. Accessed 26 March 2020.

4. Österreichisches Krebsregister (Stand 09.12.2019) und Todesursachenstatistik. Prostata (C61) - Krebsinzidenz (Neuerkrankungen pro Jahr), Österreich ab 1983. 2019. http://pic.statistik.at/web_de/statistiken/menschen_und_ gesellschaft/gesundheit/krebserkrankungen/prostata/ 021791.html. Accessed 26 March 2020.

5. Hasenoehrl T, Keilani M, Sedghi Komanadj T, Mickel M, Margreiter M, Marhold M, et al. The effects of resistance exercise on physical performance and health-related quality of life in prostate cancer patients: a systematic review. Support Care Cancer. 2015;23:2479-97. https://doi.org/10. 1007/s00520-015-2782-x.

6. Keilani M, Hasenoehrl T, Baumann L, Ristl R, Schwarz M, Marhold M, et al. Effects of resistance exercise in prostate cancer patients: a meta-analysis. Support Care Cancer. 2017;25(9):2953-2968. https://doi.org/10.1007/ s00520-017-3771-z.

7. Attard G, Parker C, Eeles RA, Schroder F, Tomlins SA, TannockI, et al. Prostate cancer. Lancet. 2016;387:70-82.

8. Rhee H, Gunter JH, Heathcote P, Ho K, Stricker P, Corcoran NM, et al. Adverse effects of androgen-deprivation therapy in prostate cancer and their management. BJU Int. 2015;115:3-13.

9. Hamilton K, Chambers SK, Legg M, Oliffe JL, Cormie P. Sexuality and exercise in men undergoing androgen deprivation therapy for prostate cancer. Support Care Cancer. 2015;23:133-42.

10. Ottenbacher A, Sloane R, Snyder DC, Kraus W, Sprod L, Demark-Wahnefried W. Cancer-specific concerns and physical activity among recently diagnosed breast and prostate cancer survivors. Integr Cancer Ther. 2012;12:206-12. https://doi.org/10.1177/1534735412449734.

11. Ng E, Woo HH, Turner S, Leong E, Jackson M, Spry N. The influence of testosterone suppression and recovery on sexual function in men with prostate cancer: observations from a prospective study in men undergoing intermittent androgen suppression. J Urol. 2012;187:2162-7. https:// doi.org/10.1016/j.juro.2012.01.080.

12. Peltier $A$, van Velthoven R, Roumeguère T. Current management of erectile dysfunction after cancer treatment. Curr Opin Oncol. 2009; https://doi.org/10.1097/CCO. 0b013e32832b9d76.

13. CormieP, NewtonRU, TaaffeDR, SpryN, GalvãoDA.Exercise therapy for sexual dysfunction after prostate cancer. Nat Rev Urol. 2013;10:731-6. https://doi.org/10.1038/nrurol. 2013.206.

14. Oliffe J. Constructions of masculinity following prostatectomy-inducedimpotence. SocSciMed. 2005;60:2249-59. 
15. Bourke L, Doll H, Crank H, Daley A, Rosario D, Saxton JM. Lifestyle intervention in men with advanced prostate cancer receiving androgen suppression therapy: a feasibility study. Cancer Epidemiol Biomarkers Prev. 2011;20:647-57.

16. BourkeL, GilbertS, Hooper R, SteedLA, Joshi M, CattoJWF, et al. Lifestyle changes for improving disease-specific quality of life in sedentary men on long-term androgen-deprivation therapy for advanced prostate cancer: a randomised controlled trial. Eur Urol. 2014;65:865-72.

17. Cormie P, Newton RU, Spry N, Joseph D, Taaffe DR, Galvão DA. Safety and efficacy of resistance exercise in prostate cancer patients with bone metastases. Prostate Cancer Prostatic Dis. 2013;16:328-35. https://doi.org/10. 1038/pcan.2013.22.

18. Cormie P, Galvao DA, Spry N, Joseph D, Chee R, Taaffe DR, et al. Can supervised exercise prevent treatment toxicity in patients with prostate cancer initiating androgen-deprivation therapy: a randomised controlled trial. BJU Int. 2015;115:256-66.

19. Galvão DA, Nosaka K, Taffee DR, Spry N, Kristjanson LJ, McGuigan MR, et al. Resistance training and reduction of treatment side effects in prostate cancer patients. Med Sci Sports Exerc. 2006;38:2045-52.

20. Galvão DA, Taaffe DR, Spry N, Joseph D, Newton RU. Combined resistance and aerobic exercise program reverses muscle loss in men undergoing androgen suppression therapy for prostate cancer without bone metastases: A randomized controlled trial. JClin Oncol. 2010;28:340-7.

21. Galvão DA, Spry N, Denham J, Taaffe DR, CormieP, JosephD, et al. A multicentre year-long randomised controlled trial of exercise training targeting physical functioning in men with prostate cancer previously treated with androgen suppression and radiation from TROG03.04 radar. Eur Urol. 2014;65:856-64.

22. HansonED, SheaffAK, Sood S, MaL, FrancisJD, GoldbergAP, et al. Strength training induces muscle hypertrophy and functional gains in black prostate cancer patients despite androgen deprivation therapy. Journals Gerontol Ser A. 2013;68:490-8. https://doi.org/10.1093/gerona/gls206.

23. Mina DS, Alibhai SMH, Matthew AG, Guglietti CL, Pirbaglou M, Trachtenberg J, et al. A randomized trial of aerobic versus resistance exercise in prostate cancer survivors. JAging Phys Act. 2013;21:455-78.

24. Park SW, Kim TN, Nam JK, Ha HK, Shin DG, Lee W, et al. Recovery of overall exercise ability, quality of life, and continence after 12-week combined exercise intervention in elderly patients who underwent radical prostatectomy: a randomized controlled study. Urology. 2012;80:299-305.

25. Segal RJ. Resistance exercise in men receiving androgen deprivation therapy for prostate cancer. J Clin Oncol. 2003;21:1653-9. https://doi.org/10.1200/JCO.2003.09.534.

26. Segal RJ, Reid RD, Courneya KS, Sigal RJ, Kenny GP, Prud'Homme DG, et al. Randomized controlled trial of resistance or aerobic exercise in men receiving radiation therapy for prostate cancer. J Clin Oncol. 2009;27:344-51. https://doi.org/10.1200/JCO.2007.15.4963.

27. Winters-Stone MK, Dobek CJ, Bennett AJ, Maddalozzo FG, Ryan WC, Beer MT. Skeletal response to resistance and impact training in prostate cancer survivors. Med SciSports Exerc. 2014;46:1482-8.

28. Livingston PM, Craike MJ, Salmon J, Courneya KS, Gaskin CJ, Fraser SF, et al. Effects of a clinician referral and exercise program for men who have completed active treatment for prostate cancer: a multicenter cluster randomized controlled trial (ENGAGE). Cancer. 2015;121:2646-54.

29. Nilsen TS, Raastad T, Skovlund E, Courneya KS, Langberg CW, Lilleby W, et al. Effects of strength training on body composition, physical functioning, and quality of life in prostate cancer patients during androgen deprivation therapy. Acta Oncol. 2015;54:1805-13. https://doi.org/10. 3109/0284186X.2015.1037008.

30. Winters-Stone KM, Lyons KS, Dobek J, Dieckmann NF, Bennett JA, Nail L, et al. Benefits of partnered strength training for prostate cancer survivors and spouses: results from a randomized controlled trial of the Exercising Together project. J Cancer Surviv. 2016;10:633-44. https://doi.org/ 10.1007/s11764-015-0509-0.

31. Hojan K, Kwiatkowska-Borowczyk E, Leporowska E, Gorecki M, Ozga-Majchrzak O, Milecki T, et al. Physical exercise for functional capacity, blood immune function, fatigue and quality of life in high-risk prostate cancer patients during radiotherapy. A prospective, randomised clinical study. Eur J Phys Rehabil Med. 2016;52:489-501.

32. Alberga AS, Segal RJ, Reid RD, Scott CG, Sigal RJ, Khandwala F, et al. Age and androgen-deprivation therapy on exercise outcomes in men with prostate cancer. Support Care Cancer. 2012;20:971-81.

33. Buffart LM, Galvão DA, Chinapaw MJ, Brug J, Taaffe DR, Spry N, et al. Mediators of the resistance and aerobic exercise intervention effect on physical and general health in men undergoing androgen deprivation therapy for prostate cancer. Cancer. 2014;120:294-301.

34. Cormie P, Newton RU, Taaffe DR, Spry N, Joseph D, Akhlil Hamid $\mathrm{M}$, et al. Exercise maintains sexual activity in menundergoing androgen suppressionfor prostatecancer: a randomized controlled trial. Prostate Cancer Prostatic Dis. 2013;16:170-5.

35. Galvão DA, Nosaka K, Taaffe DR, Peake J, Spry N, Suzuki K, et al. Endocrine and immune responses to resistance training in prostate cancer patients. Prostate Cancer Prostatic Dis. 2008;11:160-5. https://doi.org/10.1038/sj. pcan.4500991.

36. Courneya KS, Segal RJ, Reid RD, Jones LW, Malone SC, Venner PM, et al. Three independent factors predicted adherence in a randomized controlled trial of resistance exercise training among prostate cancer survivors. J Clin Epidemiol. 2004;57:571-9.

37. Galvão DA, Taaffe DR, Spry N, Joseph D, Newton RU. Acute versus chronic exposure to androgen suppression for prostate cancer: impact on the exercise response. J Urol. 2011;186:1291-7. https://doi.org/10.1016/j.juro.2011.05. 055.

38. Mina DS, Connor MK, Alibhai SMH, Toren P, Guglietti C, Matthew AG, et al. Exercise effects on adipokines and the IGF axis in men with prostate cancer treated with androgen deprivation: a randomized study. Can Urol Assoc J. 2013;7:E692-E8.

39. Winters-Stone KM, Dobek JC, Bennett JA, Dieckmann NF Maddalozzo GF, Ryan CW, et al. Resistance training reduces disabilityin prostate cancer survivors on androgendeprivation therapy: evidence from a randomized controlled trial. Arch Phys Med Rehabil. 2014;96:7-14.

40. Gaskin CJ, Fraser SF, Owen PJ, Craike M, Orellana L, Livingston PM. Fitness outcomes from a randomised controlled trial of exercise training for men with prostate cancer: the ENGAGE study. J Cancer Surviv. 2016; https:// doi.org/10.1007/s11764-016-0543-6.

41. Nilsen TS, Thorsen L, Fosså SD, Wiig M, Kirkegaard C, Skovlund E, et al. Effects of strength training on muscle cellular outcomes in prostate cancer patients on androgen deprivation therapy. Scand J Med Sci Sports. 2015;26:1026-35. https://doi.org/10.3109/0284186X.2015.1037008.

42. Nilsen TS, Thorsen L, Kirkegaard C, Ugelstad I, Fosså SD, Raastad T. The effect of strength training on muscle cellular 
stress in prostate cancer patients on ADT. Endocr Connect. 2016;5:74-82.

43. Buffart LM, Newton RU, Chinapaw MJ, Taaffe DR, Spry NA, Denham JW, et al. The effect, moderators, and mediators of resistance and aerobic exercise on health-related quality of life in older long-term survivors of prostate cancer. Cancer. 2015;121:2821-30.

44. Gilbert SE, Tew GA, Fairhurst C, Bourke L, Saxton JM, WinterEM, etal. Effects of a lifestyle intervention on endothelial function in men on long-term androgen deprivation therapy for prostate cancer. Br JCancer. 2016;114:401-8.

45. Lyons KS, Winters-Stone KM, Bennett JA, Beer TM. The effects of partnered exercise on physical intimacy in couples coping with prostate cancer. Health Psychol. 2016;35:509-13.

46. Winters-Stone KM, Dieckmann N, Maddalozzo GF, Bennett JA, Ryan CW, Beer TM. Resistance exercise reduces body fat and insulin during androgen-deprivation therapy for prostate cancer. ONF. 2015;42:348-56.

47. Gazova A, Samakova A, Laczo E, Hamar D, Polakovicova M, Jurikova M, et al. Clinical utility of miRNA-1, miRNA-29g and miRNA-133s plasma levels in prostate cancer patients with high-intensity training after androgen-deprivation therapy. Physiol Res. 2019;68:S139-S47.

48. Ndjavera W, Orange ST, O'Doherty AF, Leicht AS, Rochester M, Mills R, et al. Exercise-induced attenuation of treatment side-effects in patients with newly diagnosed prostate cancer beginning androgen-deprivation therapy: a randomised controlled trial. BJU Int. 2020;125:28-37.

49. Newton RU, Galvão DA, Spry N, Joseph D, Chambers SK, Gardiner RA, et al. Exercise mode specificity for preserving spine and hip Bone mineral density in prostate cancer patients. Med Sci Sports Exerc. 2019;51:607-14.

50. Taaffe DR, Galvão DA, Spry N, Joseph D, Chambers SK, Gardiner RA, et al. Immediate versus delayed exercise in men initiating androgen deprivation: effects on bone density and soft tissue composition. BJU Int. 2019;123:261-9.

51. Galvão DA, Taaffe DR, Spry N, Cormie P, Joseph D, Chambers SK, et al. Exercise preserves physical function in prostate cancer patients with bone metastases. Med Sci Sports Exerc. 2018;50:393-9.

52. Wall BA, Galvão DA, Fatehee N, Taaffe DR, Spry N, Joseph D, et al. Exercise improves VO2max and body composition in androgen deprivation therapy-treated prostate cancer patients. Med Sci Sports Exerc. 2017;49:1503-10.

53. Taaffe DR, Newton RU, Spry N, Joseph D, Chambers SK, Gardiner RA, et al. Effects of different exercise modalities onfatiguein prostate cancer patients undergoing androgen deprivation therapy: a year-long randomised controlled trial. Eur Urol. 2017;72:293-9.

54. Newton RU, Galvão DA, Spry N, Joseph D, Chambers SK, Gardiner RA, et al. Timing of exercise for muscle strength and physical function in men initiating ADT for prostate cancer. Prostate Cancer Prostatic Dis. 2020; https://doi. org/10.1038/s41391-019-0200-z.

55. Fairman CM, Nilsen TS, Newton RU, Taaffe DR, Spry N, Joseph D, et al. Reporting of resistance training dose, adherence, and tolerance in exercise oncology. Med Sci Sports Exerc. 2020;52:315-22.

56. Edmunds K, Reeves P, Scuffham P, Galvão DA, Newton RU, Jones $\mathrm{M}$, et al. Cost-effectiveness analysis of supervised exercise training in men with prostate cancer previously treated with radiation therapy and androgen-deprivation therapy. Appl Health Econ Health Policy. 2020; https:// doi. org/10.1007/s40258-020-00564-x.
57. Galvão DA, Taaffe DR, Spry N, Cormie P, Joseph D, Chambers SK, et al. Exercise Preserves Physical Function in Prostate Cancer Patients with Bone Metastases. Med Sci Sports Exerc. 2018; https://doi.org/10.1249/MSS. 0000000000001454.

58. Druley JA, Stephens MAP, Coyne JC. Emotional and physical intimacy in coping with lupus: women's dilemmas of disclosure and approach. Health Psychol. 1997;16:506-14.

59. Cunningham HC, West DWD, Baehr LM, Tarke FD, Baar K, Bodine SC, et al. Age-dependent bone loss and recovery during hindlimb unloading and subsequent reloading in rats. BMC Musculoskelet Disord. 2018;19(1):223. https:// doi.org/10.1186/s12891-018-2156-x.

60. Harvey NC, Odén A, Orwoll E, Lapidus J, Kwok T, Karlsson MK, et al. Measures of physical performance and muscle strength as predictors of fracture risk independent of FRAX, falls, and aBMD: a meta-analysis of the osteoporotic fractures in men (mrOS) study. J Bone Miner Res. 2018;33:2150-7. https://doi.org/10.1002/jbmr.3556.

61. Sherrington C, Fairhall NJ, Wallbank GK, Tiedemann A, Michaleff ZA, Howard K, et al. Exercise for preventing falls in older people living in the community. Cochrane Database Syst Rev. 2019; https://doi.org/10. 1002/14651858.CD012424.pub2.

62. Sedgwick P. Pitfalls of statistical hypothesis testing: type I and type II errors. BMJ. 2014;349:g4287. https://doi.org/10. 1136/bmj.g4287.

63. Winters-Stone KM, Neil SE, Campbell KL. Attention to principles of exercise training: a review of exercise studies for survivors of cancers other than breast. Br J Sports Med. 2014;48:987-95.

64. Moher D, Hopewell S, Schulz KF, Montori V, Gøtzsche PC, Devereaux PJ, et al. CONSORT 2010 explanation and elaboration: updated guidelines for reporting parallel group randomised trials. BMJ. 2010;63(8):el-e37. https:// doi.org/10.1016/j.jclinepi.2010.03.004.

65. Bland JM, Altman DG. Comparisons against baseline within randomised groups are often used and can be highly misleading. Trials. 2011;12:264. https://doi.org/10.1186/ 1745-6215-12-264.

66. Gonnermann A, Framke T, Großhennig A, Koch A. No solution yet for combining two independent studies in the presence of heterogeneity. Stat Med. 2015;34:2476-80.

67. Hilfiker R, Meichtry A, Eicher M, Nilsson Balfe L, Knols RH, Verra ML, et al. Exercise and other non-pharmaceutical interventions for cancer-related fatigue in patients during oraftercancer treatment: asystematicreviewincorporating an indirect-comparisons meta-analysis. Br J Sports Med. 2018;52:651-8.

68. Liu C-J, Latham NK. Progressive resistance strength training for improving physical function in older adults. Cochrane Database Syst Rev. 2009; https://doi.org/10. 1002/14651858.CD002759.pub2.

69. Lee DM, Nazroo J, O'Connor DB, Blake M, Pendleton N. Sexual health and well-being among older men and women in england: findings from the English longitudinal study of ageing. Arch Sex Behav. 2016;45:133-44.

70. Corona G, Lee DM, Forti G, O'Connor DB, Maggi M, O'Neill TW, et al. Age-related changes in general and sexual healthin middle-aged and oldermen: results from theEuropean male ageing study (EMAS). J Sex Med. 2010;7:1362-80.

71. Nelson CJ, Mulhall JP, Roth AJ. The association between erectile dysfunction and depressive symptoms in men treated for prostate cancer. J Sex Med. 2011;8:560-6.

72. Nelson CJ, Deveci S, Stasi J, Scardino PT, Mulhall JP. Sexual bother following radical prostatectomy. J Sex Med. 2010;7:129-35. 
73. Higano CS. Sexualityandintimacyafter definitivetreatment and subsequent androgen deprivation therapy for prostate cancer. JClin Oncol. 2012;30:3720-5.

74. Dote-Montero M, De-la-OA, Castillo MJ, Amaro-Gahete FJ. Predictors of sexual desire and sexual function in sedentary middle-aged adults: the role of lean mass index and S-Klotho plasma levels. The FIT-AGEING study. J Sex Med. 2020; https://doi.org/10.1016/j.jsxm.2020.01.016.

75. Fode M, Sønksen J. Sexual function in elderly men receiving androgen deprivation therapy (ADT). Sex Med Rev. 2014;2:36-46.

76. Kalter J, Kampshoff CS, Chinapaw MJM, Van Mechelen W, Galindo-Garre F, Schep G, et al. Mediators of exercise effects on HRQoL in cancer survivors after chemotherapy. Med Sci Sports Exerc. 2016;48:1859-65.

77. Virtuoso JF, Menezes EC, Mazo GZ. Effect of weight training with pelvic floor muscle training in elderly women with urinary incontinence. Res Q Exerc Sport. 2019;90:141-50.
78. Crevenna R, Dorner TE. Association between fulfilling the recommendations for health-enhancing physical activity with (instrumental) activities of daily living in older Austrians. Wien Klin Wochenschr. 2019;131:265-72. https://doi. org/10.1007/s00508-019-1511-8.

79. Keilani M, Kainberger F, Pataraia A, Hasenöhrl T, Wagner B, Palma S, et al. Typical aspects in the rehabilitation of cancer patients suffering from metastatic bone disease or multiple myeloma. Wien Klin Wochenschr. 2019;131:567-75.

80. Crevenna R. Health-enhancing physical activity, exercise and sports-a never-ending success story. Wien Klin Wochenschr. 2020;132:113-4.

Publisher's Note Springer Nature remains neutral with regard to jurisdictional claims in published maps and institutional affiliations. 